\title{
Repetitive hypoglycaemia increases serum adrenaline and induces monocyte adhesion to the endothelium in rat thoracic aorta
}

\author{
W. L. Jin • K. Azuma • T. Mita $\cdot$ H. Goto • \\ A. Kanazawa $\cdot$ T. Shimizu $\cdot$ F. Ikeda $\cdot$ Y. Fujitani $\cdot$ \\ T. Hirose $\cdot$ R. Kawamori $\cdot$ H. Watada
}

Received: 1 November 2010 /Accepted: 16 March 2011/Published online: 16 April 2011

(C) Springer-Verlag 2011

\begin{abstract}
Aims/hypothesis Severe hypoglycaemia associated with diabetes management is a potential risk for cardiovascular diseases. However, the effect and mechanism of hypoglycaemia on the progression of atherosclerosis remains largely unknown. As a first step towards elucidating the
\end{abstract}

Electronic supplementary material The online version of this article (doi:10.1007/s00125-011-2141-5) contains supplementary material, which is available to authorised users.

W. L. Jin $\cdot$ K. Azuma $\cdot$ T. Mita $(\bowtie) \cdot H$. Goto $\cdot$ A. Kanazawa $\cdot$ T. Shimizu $\cdot$ F. Ikeda $\cdot$ Y. Fujitani $\cdot$ T. Hirose $\cdot$ R. Kawamori $\cdot$

H. Watada $(\triangle)$

Department of Medicine, Metabolism and Endocrinology, Juntendo University Graduate School of Medicine,

2-1-1 Hongo, Bunkyo-ku,

Tokyo 113-8421, Japan

e-mail: tom-m@juntendo.ac.jp

e-mail: hwatada@juntendo.ac.jp

R. Kawamori $\cdot$ H. Watada

Sportology Center,

Juntendo University Graduate School of Medicine,

Tokyo, Japan

Y. Fujitani $\cdot$ T. Hirose $\cdot$ R. Kawamori

Center for Therapeutic Innovations in Diabetes,

Juntendo University Graduate School of Medicine,

Tokyo, Japan

R. Kawamori

Center for Beta Cell Biology and Regeneration, Juntendo University Graduate School of Medicine, Tokyo, Japan above, we investigated the effect of hypoglycaemia on monocyte-endothelial interaction.

Methods Insulin was injected intraperitoneally once every 3 days for 5 weeks in Goto-Kakizaki rats, a non-obese rat model of type 2 diabetes. We counted the number of monocytes adherent to the endothelium of thoracic aorta as an index of early atherosclerogenesis. Cultured HUVEC were used to investigate the mechanism of action.

Results Insulin treatment increased the number of monocytes adherent to the vascular endothelium. This increase was abrogated by injection of glucose with insulin. Amosulalol, an $\alpha-1$ and $\beta$-adrenoreceptor antagonist, suppressed monocyte adhesion to endothelium and levels of adhesion molecules (intercellular adhesion molecule- 1 and vascular cell adhesion molecule-1) in the endothelial surface, which had been enhanced by insulin-induced hypoglycaemia. In HUVEC, adrenaline (epinephrine) significantly increased nuclear translocation of nuclear factorKB (NF-kB) p65 and levels of adhesion molecules, effects that were abrogated following addition of SQ22536, a specific adenyl cyclase inhibitor.

Conclusions/interpretation Our data indicate that repetitive hypoglycaemia induced by insulin enhanced monocyte adhesion to endothelial cells in Goto-Kakizaki rat aorta through enhanced adrenaline activity and that the latter stimulated intracellular cAMP, leading to nuclear translocation of NF- $\mathrm{kB}$ with subsequent production of adhesion molecules in endothelial cells.

Keywords Adrenaline · Diabetes · Hypoglycaemia · Insulin $\cdot$ Monocyte adhesion 


$\begin{array}{ll}\begin{array}{ll}\text { Abbreviations } \\ \text { ACCORD }\end{array} & \begin{array}{l}\text { Action to Control Cardiovascular Risk in } \\ \text { Diabetes }\end{array} \\ \text { GK rat } & \begin{array}{l}\text { Goto-Kakizaki rat } \\ \text { ICAM-1 }\end{array} \\ \text { Intercellular adhesion molecule-1 } \\ \text { NF-kB } & \text { Nuclear factor-kB } \\ \text { VCAM-1 } & \text { Vascular cell adhesion molecule-1 }\end{array}$

\section{Introduction}

Diabetes mellitus is associated with a high prevalence of cardiovascular diseases. Hyperglycaemia is the most typical feature of patients with such complications [1]. However, three recent large clinical trials - the Action to Control Cardiovascular Risk in Diabetes (ACCORD) Study, the Action in Diabetes and Vascular Disease: Preterax and Diamicron Modified Release Controlled Evaluation (ADVANCE) study and the Veterans Affairs Diabetes Trial (VADT) showed that intensive glycaemic control had no beneficial effects on the prevalence of cardiovascular disease in type 2 diabetes [2-4]. In the ACCORD study in particular, excess deaths observed in the intensive treatment arm led to early discontinuation [2]. While the exact reason for the increased mortality rate despite rigorous blood glucose control is not clear, anecdotal evidence prompted us to speculate that increased frequency of episodic hypoglycaemia by rigorous blood glucose control might be implicated in the excess mortality [5]. Although recent retrospective analysis of ACCORD failed to show that symptomatic severe hypoglycaemia accounts for the excess mortality rate [6], not all hypoglycaemic episodes were monitored in that study. Thus, one cannot completely exclude the possible role of hypoglycaemia in the excess deaths and other cardiovascular events.

Hypoglycaemia is a common side effect of insulin treatment for diabetes. Strict glycaemia control using intensive insulin therapy increases the risk of hypoglycaemia. While it is well known that hypoglycaemia affects cognition, mood and consciousness, it also has profound effects on blood constituents [7,8], inflammatory cytokine level $[9,10]$, and coagulation and fibrinolysis factors [11, 12], mainly through the sympathoadrenal response to hypoglycaemia. These data suggest that hypoglycaemia induced by insulin injection may be implicated in the progression of atherosclerosis; however, there are no convincing in vivo data in support of this hypothesis.

The adhesion of circulating monocytes to intimal endothelial cells is thought to be one of the earliest events in atherosclerogenesis [13]. Endothelial leucocyte adhesion molecule-1, intercellular adhesion molecule-1 (ICAM-1) and vascular cell adhesion molecule-1 (VCAM-1) are three of the most important molecules associated with monocyte adhesion to endothelium. The attached monocytes are thought to invade and play a role in inflammation of the vascular wall.

In the present study, as a first step towards assessing the impact of insulin-induced hypoglycaemia on atherosclerogenesis, we investigated its effect on monocyte adhesion to the endothelium using Goto-Kakizaki (GK) rats, a non-obese model of type 2 diabetes.

\section{Methods}

Animal experiments

The study protocol was reviewed and approved by the Animal Care and Use Committee of Juntendo University. Male GK rats were purchased from Sankyo Lab Service (Tokyo, Japan) at the age of 7 weeks and housed in polycarbonate cages with wooden chip mats on the floor. All rats had free access to diet and water. Standard chow (22.6\% protein, $53.8 \%$ carbohydrate, $5.6 \%$ fat, $6.6 \%$ mineral and vitamin mixture, and $3.3 \%$ fibre; total energy 1,495 kcal/100 g; CRF-1; Charles River Japan, Yokohama, Japan) was used in this study. The animal room was kept on a $12 \mathrm{~h}$ reverse light-dark cycle (07:00 to 19:00 hours dark, 19:00 to 07:00 hours light), at a constant temperature $\left(22 \pm 1^{\circ} \mathrm{C}\right)$ and relative humidity of $55 \pm 5 \%$ throughout the experimental period.

To investigate the effect of hypoglycaemia, 9-week-old GK rats were divided into three groups: saline, insulin and insulin + glucose. The mean body weight and blood glucose level were comparable among the groups. Rats of the saline group $(n=6)$ received i.p. injections of $5 \mathrm{ml} / \mathrm{kg}$ body weight saline at 0,30 and $60 \mathrm{~min}$. Rats of the insulin group $(n=6)$ received i.p. injections of $15 \mathrm{U} / \mathrm{kg}$ body weight insulin mixed in $5 \mathrm{ml} / \mathrm{kg}$ body weight saline at $0 \mathrm{~min}$ and $5 \mathrm{ml} / \mathrm{kg}$ body weight saline at 30 and $60 \mathrm{~min}$. GK rats of the insulin + glucose group $(n=6)$ received i.p. injections of $15 \mathrm{U} / \mathrm{kg}$ body weight insulin and $1.5 \mathrm{~g} / \mathrm{kg}$ body weight glucose at $0 \mathrm{~min}$ followed by $1.0 \mathrm{~g} / \mathrm{kg}$ glucose at 30 and $60 \mathrm{~min}$ after the first injection, respectively. Each set of the treatment was administered once every 3 days for 5 weeks. At the age of 14 weeks, rats of each group were killed to evaluate the atherosclerotic changes.

To investigate the effect of catecholamine, 9-week-old GK rats were divided into four groups with or without amosulalol, an $\alpha-1$ and $\beta$-adrenoreceptor blocker, as follows: saline without amosulalol, insulin without amosulalol, saline with amosulalol and insulin with amosulalol. The mean body weight and blood glucose levels were comparable among the groups. Rats of the saline group $(n=12)$ received i.p. injections of $3 \mathrm{ml} / \mathrm{kg}$ body weight saline. Rats of the insulin group $(n=12)$ received i.p. 
injections of $15 \mathrm{U} / \mathrm{kg}$ body weight insulin. GK rats of the saline with amosulalol group $(n=12)$ received i.p. injections of $3 \mathrm{ml} / \mathrm{kg}$ body weight saline and were fed amosulalolcontaining diet $(200 \mathrm{mg} / \mathrm{kg})$. Finally, rats of the insulin with amosulalol group $(n=12)$ received i.p. injections of $15 \mathrm{U} / \mathrm{kg}$ body weight insulin and were fed amosulalol-containing diet $(200 \mathrm{mg} / \mathrm{kg})$. Each set of the treatment was performed once every 3 days for 5 weeks. At the age of 14 weeks, rats of each group were killed to evaluate atherosclerotic changes.

\section{Blood tests}

Fasting plasma glucose levels were measured by glucose oxidase method using a glucose analyser (One Touch Ultra Glucose Meter; Life Scan, Tokyo, Japan). Glycohaemoglobin levels were measured by ion-exchange high-performance liquid chromatography (23 GHbV; Toso, Tokyo, Japan). Total cholesterol, HDL and triacylglycerol were measured by Skylight Biotech (Tokyo, Japan). Adrenaline (epinephrine), noradrenaline (norepinephrine) and dopamine levels were measured by SRL (Tachikawa, Japan).

\section{En face immunohistochemistry of endothelial surface}

Monocyte adhesion to the thoracic aorta was quantified by en face immunohistochemistry, as described previously [14-18]. Briefly, rats ( $n=6$ from each group) were killed under anaesthesia induced by i.p. injection of sodium pentobarbital (50 mg/kg; Abbott Laboratories, Abbott Park, IL, USA) then perfused with normal saline followed by $10 \%$ (wt/vol.) buffered formalin. After fixation, the aorta was divided into 8- to 10 -mm-long segments. Each segment was then placed in $0.05 \%$ hydrogen peroxidase in methanol for $20 \mathrm{~min}$ at room temperature. These specimens were incubated for $60 \mathrm{~min}$ at $37^{\circ} \mathrm{C}$ with mouse anti-rat CD68 antibodies (Serotec, Raleigh, NC, USA), diluted 1:100 in phosphate-buffered saline. Next, the specimens were placed with biotinylated anti-mouse $\mathrm{IgG}$ for $30 \mathrm{~min}$ at room temperature, followed by reaction with horseradish peroxidase-conjugated streptavidin with the aid of a kit (LSAB2; Dako, Carpinteria, CA, USA). Staining was completed after incubation with a substrate-chromogen solution. The segments were then cut open longitudinally along the ventral side with the intimal side up and covered with a coverslip by surface tension. Specimens were viewed under a microscope (E800; Nikon, Tokyo, Japan) as described previously [14]. The density of CD68-immunopositive cells in the thoracic aorta was calculated by examiners blinded to the treatment regimen, as described previously [14, 15]. ICAM-1 and VCAM-1 abundance was also evaluated by enface immunostaining using the thoracic aorta of each group (ICAM-1, $n=6$ each; VCAM-1, $n=6$ each). Anti-rat
ICAM-1 antibody (Oxford Biotechnology, Oxford, UK) and anti-VCAM-1 antibody (Santa Cruz Biotechnology, Santa Cruz, CA, USA) were used for detection. The abundance of ICAM-1 and VCAM-1 was determined by calculating the percentage of ICAM-1 - or VCAM-1-positive area relative to total cross-sectional endothelial surface area by examiners blinded to the treatment regimen.

\section{Quantification of intimal thickening}

Four cross-sections of paraffin-embedded aorta spaced at approximately $4 \mathrm{~mm}$ intervals were stained with Azan to measure intimal areas of the thoracic aorta. The cross-sectional intimal areas of a lesion in a given photomicrograph were measured with image analysis software (Image-Pro4.5J; Planetron, Tokyo, Japan). The average intimal area was determined as described previously [14].

\section{Cell cultures}

HUVEC were purchased from Lonza (Basel, Switzerland) and maintained at $37^{\circ} \mathrm{C}$ under a humidified atmosphere of $95 \%$ air and $5 \% \mathrm{CO}_{2}$ in endothelial cell growth medium (Lonza, Walkersville, ML,USA) that was supplemented with endothelial growth medium 2 kit (Lonza) containing various supplements and growth factors. For all experiments, cells were used within passage six. Overnight serum-starved HUVEC were washed once and then incubated without or with 1, 10 and $100 \mu \mathrm{mol} / \mathrm{l}$ adrenaline for $24 \mathrm{~h}$. To investigate the effect of adrenaline signal, HUVEC were incubated with or without 1 , 10 and $100 \mu \mathrm{mol} / \mathrm{l}$ amosulalol for $30 \mathrm{~min}$ before adding $10 \mu \mathrm{mol} / 1$ adrenaline. Similarly, HUVEC were incubated without or with $10 \mu \mathrm{mol} / 1$ SQ22536 (Sigma-Aldrich, St Louis, MO, USA), an adenylate cyclase inhibitor, for $30 \mathrm{~min}$ before adding $10 \mu \mathrm{mol} / 1$ adrenaline. As a control, HUVEC were incubated with DMSO (final concentration $<0.1 \%$ ).

Isolation of tissue RNA and real-time quantitative RT-PCR

Total RNA was extracted from the aorta using Trizol reagent (Invitrogen, Carlsbad, CA, USA) and from HUVEC using a kit (RNAeasymicro; Qiagen, Tokyo, Japan) using the instructions supplied by the manufacturer. First strand cDNA was synthesised using $2 \mu \mathrm{g}$ total RNA with random primers and superscript reverse transcriptase (Invitrogen). The resulting cDNAs were amplified usinga buffer (SYBR Green PCR Master Mix; Applied Biosystems, Foster City, CA, USA). Quantitative PCR was performed with a detection system (ABI Prism 7500; Perkin Elmer Life Sciences, Boston, MA, USA). The relative abundance of mRNAs was calculated by the comparative cycle of threshold method with TATA box-binding protein as the 
invariant control. The primer sequences used in this study are described in electronic supplementary material (ESM) Table 1.

Quantification of nuclear factor-kB

Nuclear protein extracts were isolated from HUVEC and nuclear factor- $\mathrm{kB}(\mathrm{NF}-\mathrm{kB})$ p 65 content was determined by specific ELISA kit (Imgenex, San Diego, CA, USA) as described previously [18].

\section{Statistical analysis}

Results are presented as mean \pm SEM. Differences between two groups were examined for statistical significance using the unpaired Student's $t$ test. Comparisons of more than three groups were conducted by one-way ANOVA followed by Scheffé's method as the post hoc test. A value of $p<0.05$ was considered significant.

\section{Results}

\section{Animal experiments}

Injection of excess insulin induces hypoglycaemia Blood glucose level was not altered in the saline group, but was diminished in the insulin group to $3.0 \pm 0.1 \mathrm{mmol} / \mathrm{l}$ at $30 \mathrm{~min}$, staying low for some time, then gradually rising at 120 min after the injection (Fig. 1). On the other hand, blood glucose level was more than $4.5 \pm 0.4 \mathrm{mmol} / 1$ in the insulin + glucose group (Fig. 1). These results indicate that injection of insulin with glucose prevents insulin-induced hypoglycaemia. To assess induction of sympathetic nerve activity by hypoglycaemia, we measured serum catechol-

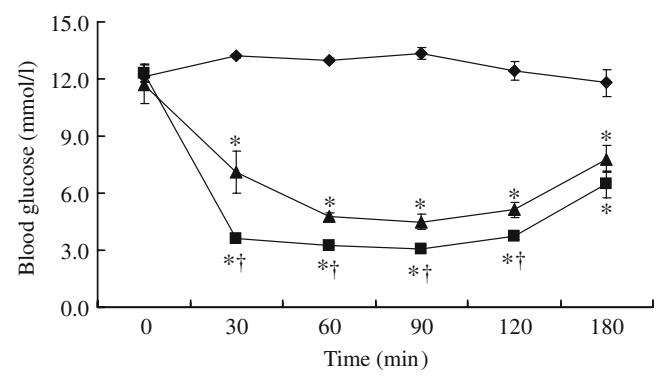

Fig. 1 Excess insulin induces hypoglycaemia. Blood glucose levels were measured at the indicated time points following i.p. injections in 9-week-old GK rats as follows: (1) $5 \mathrm{ml} / \mathrm{kg}$ body weight saline at 0,30 and $60 \mathrm{~min}$ (diamonds, $n=5$ ); (2) $15 \mathrm{U} / \mathrm{kg}$ body weight insulin mixed with $5 \mathrm{ml} / \mathrm{kg}$ body weight saline at $0 \mathrm{~min}$ and $5 \mathrm{ml} / \mathrm{kg}$ body weight saline at 30 and $60 \mathrm{~min}$ (squares, $n=5$ ); and (3) $15 \mathrm{U} / \mathrm{kg}$ body weight insulin and $1.5 \mathrm{~g} / \mathrm{kg}$ body weight glucose at $0 \mathrm{~min}$, followed by $1.0 \mathrm{~g} / \mathrm{kg}$ body weight glucose at 30 and $60 \mathrm{~min}$ (triangles, $n=5$ ). Data are mean \pm SEM. ${ }^{*} p<0.05$ vs the saline-injected group; ${ }^{\dagger} p<0.05$ vs the insulin + glucose-injected group amine level after each treatment. As shown in Table 1, the serum catecholamine level was higher in the insulin group than in the saline group, but this was not the case in the insulin + glucose group.

Increased monocyte adhesion to the vascular endothelium by excess insulin-induced hypoglycaemia After 5 weeks of treatment (Fig. 2a), the number of monocytes adherent to the aortic endothelium was significantly larger in the insulin group than in the saline and insulin + glucose groups (Fig. 2b). These results demonstrate that repetitive hypoglycaemic episodes, not insulin injection by itself, enhances monocyte adhesion to the vascular endothelium.

Amosulalol inhibits hypoglycaemia-induced rise in serum adrenaline Amosulalol blocks the effect of $\alpha-1$ and $\beta$ adrenaline receptors and is known to inhibit the secretion of catecholamine from presynaptic neurons. Insulin injection induced hypoglycaemia with a significant increase in plasma adrenaline and noradrenaline. In contrast, insulin injection into animals fed amosulalol-containing diet prevented any rise in plasma catecholamine level, despite the presence of hypoglycaemia (Table 2). In this regard, administration of amosulalol alone did not affect basal catecholamine level. These results indicate that amosulalol inhibits any rise in catecholamine level induced by hypoglycaemia.

Amosulalol inhibits hypoglycaemia-induced increase in monocyte adhesion to the vascular endothelium In 14week-old GK rats after 5 weeks of treatment (Fig. 3a), fasting glucose level was comparable among the four experimental groups. On the other hand, $\mathrm{HbA}_{1 \mathrm{c}}$ level was significantly lower in the insulin without amosulalol group than in the other groups. Total cholesterol and HDL levels were significantly lower in the insulin with than in the insulin without amosulalol group. Total cholesterol level was also significantly lower in the saline with amosulalol group than in the corresponding group without amosulalol. Also the HDL level tended to be lower in the former than in

Table 1 Blood glucose and serum catecholamine levels at $60 \mathrm{~min}$ after i.p. injection of each solution

\begin{tabular}{lllc}
\hline Variable & $\begin{array}{l}\text { Saline } \\
(n=6)\end{array}$ & $\begin{array}{l}\text { Insulin } \\
(n=6)\end{array}$ & $\begin{array}{l}\text { Insulin+glucose } \\
(n=6)\end{array}$ \\
\hline Glucose $(\mathrm{mmol} / \mathrm{l})$ & $10.7 \pm 0.2$ & $2.9 \pm 0.1^{\mathrm{a}, \mathrm{b}}$ & $5.7 \pm 0.4$ \\
Adrenaline $(\mathrm{nmol} / \mathrm{l})$ & $42.0 \pm 9.1$ & $98.2 \pm 7.4^{\mathrm{a}, \mathrm{b}}$ & $49.3 \pm 9.2$ \\
Noradrenaline $(\mathrm{nmol} / \mathrm{l})$ & $14.1 \pm 2.6$ & $28.0 \pm 5.0^{\mathrm{a}, \mathrm{b}}$ & $13.0 \pm 1.4$ \\
Dopamine $(\mathrm{nmol} / \mathrm{l})$ & $0.46 \pm 0.05$ & $0.46 \pm 0.03$ & $0.36 \pm 0.05$ \\
\hline
\end{tabular}

Data are mean \pm SEM

${ }^{\mathrm{a}} p<0.05$ vs saline; ${ }^{\mathrm{b}} p<0.05$ vs insulin + glucose 


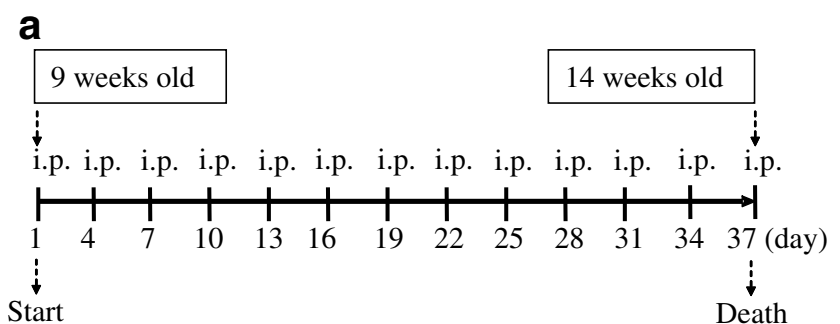

b

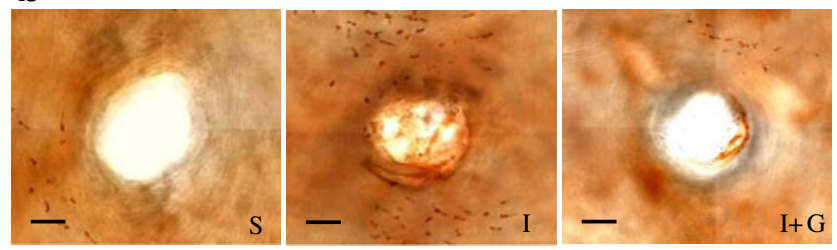

C

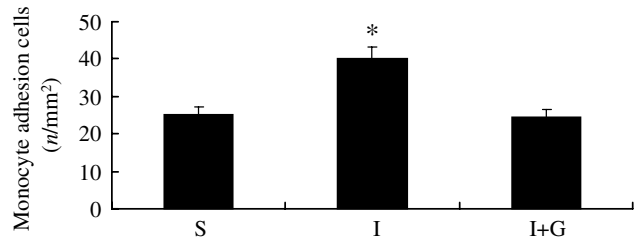

Fig. 2 Hypoglycaemia increases monocyte adhesion to endothelial cells in rat aorta. a Experimental protocol. b Representative en face photomicrographs of immunohistochemical staining using CD68 antibody for each group. Scale bar, $100 \mu \mathrm{m}$. c The density of adherent CD68-positive cells on endothelial cells at the age of 14 weeks $(n=6$ per group). Data are mean $\pm \mathrm{SEM} ;{ }^{*} p<0.05$ vs the saline and insulin + glucose groups. S, Saline group; I, insulin group; $\mathrm{I}+\mathrm{G}$, insulin+ glucose group

the latter group (Table 3). These results indicate that amosulalol tends to reduce HDL and total cholesterol levels. Basal plasma adrenaline levels were significantly higher in the insulin without amosulalol group than in the other groups. Amosulalol suppressed the increase in plasma adrenaline level. On the other hand, basal plasma noradren-

Table 2 Blood glucose and serum catecholamine levels at $60 \mathrm{~min}$ after i.p. injection of saline or insulin under normal diet or on diet containing amosulalol

\begin{tabular}{lcccc}
\hline Variable & Saline & Insulin & $\begin{array}{l}\text { Saline+ } \\
\text { amosulalol }\end{array}$ & $\begin{array}{l}\text { Insulin+ } \\
\text { amosulalol }\end{array}$ \\
\hline$n$ & 6 & 6 & 6 & 6 \\
$\begin{array}{c}\text { Glucose } \\
(\mathrm{mmol} / \mathrm{l})\end{array}$ & $11.5 \pm 0.3$ & $3.0 \pm 0.1^{\mathrm{a}}$ & $11.7 \pm 0.2$ & $3.0 \pm 0.1^{\mathrm{b}}$ \\
$\begin{array}{c}\text { Adrenaline } \\
(\mathrm{nmol} / \mathrm{l})\end{array}$ & $37.9 \pm 11.4$ & $94.1 \pm 19.9^{\mathrm{a}}$ & $28.8 \pm 10.6$ & $41.8 \pm 8.8$ \\
$\begin{array}{c}\text { Noradrenaline } \\
(\mathrm{nmol} / \mathrm{l})\end{array}$ & $10.7 \pm 2.4$ & $22.0 \pm 5.7^{\mathrm{a}}$ & $12.4 \pm 2.2$ & $9.9 \pm 0.9$ \\
$\begin{array}{c}\text { Dopamine } \\
(\mathrm{nmmol} / \mathrm{l})\end{array}$ & $0.4 \pm 0.1$ & $0.4 \pm 0.1$ & $0.4 \pm 0.1$ & $0.4 \pm 0.1$ \\
\hline
\end{tabular}

Data are mean \pm SEM

${ }^{\mathrm{a}} p<0.05$ vs saline-injected group; ${ }^{\mathrm{b}} p<0.05$ vs saline-injected group with amosulalol aline and dopamine levels were comparable among the groups (Table 3).

As shown in Fig. 3b, the number of monocytes attached to the endothelium was significantly higher in the insulin without amosulalol than in the saline without amosulalol group. While amosulalol by itself did not alter the number of monocytes attached to the vascular endothelium, it inhibited the insulin-induced increase in monocyte adhesion. Measurement of intimal thickness in each group showed significant thickening in the insulin without amosulalol group, but not in the other groups (Fig. 3c). In addition, abundance of ICAM-1 and VCAM-1 in endothelial surface of the insulin without amosulalol group was significantly increased compared with that of other groups (Fig. 4). These results suggest that the enhanced adrenaline activity induced by hypoglycaemia enhances the progression of atherosclerosis.

In vitro studies

Adrenaline increases adhesion molecule expression through cAMP signalling pathway in HUVEC The data obtained from GK rats suggest that hypoglycaemia-induced adrenaline activity enhances monocyte adhesion to the vascular endothelium. Next, we used cell cultures to investigate the direct effects of adrenaline on the expression of genes encoding adhesion molecules in HUVEC. As shown in Fig. 5a, adrenaline at 10 and $100 \mu \mathrm{mol} / \mathrm{l}$, but not at $1 \mu \mathrm{mol} / 1$ significantly increased the expression of E-selectin, Icaml and Vcaml on HUVEC. These effects were significantly inhibited in a dose-dependent manner by pre-incubation with amosulalol (Fig. 5b). Adrenaline receptor is a $\mathrm{G}_{\mathrm{s}}$ protein-coupled receptor [19], thus its activation results in increased cAMP concentration based on activation of adenylate cyclase. To confirm that the adrenaline-induced increase in E-selectin, Icaml and Vcaml expression was mediated by increased cAMP levels, HUVEC were preincubated with SQ22536, a specific adenyl cyclase inhibitor. The addition of SQ22536 significantly suppressed adrenaline-induced E-selectin, Icam1 and Vcam1 expression (Fig. 5c). Since NF-kB is a major regulator of expression of E-selectin, Icaml and Vcaml [20-22], it is possible that the adrenaline signal modulates NF- $\mathrm{kB}$ activation, which in turn enhances expression of adhesion molecules. In the final experiment, we investigated the effects of adrenaline on the nuclear abundance of NF-kB p65 in HUVEC. The addition of adrenaline markedly increased the nuclear abundance of NF- $\mathrm{KB}$ p 65 , an effect that was completely abolished by SQ22536 (Fig. 5d). These results indicate that adrenaline promotes nuclear translocation of NF- $\mathrm{kB}$ p65 by activating cAMP, in parallel with increased expression of E-selectin, Icam1 and Vcaml. 


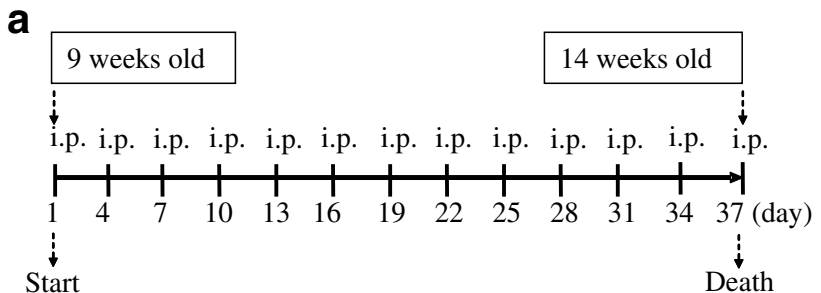

b
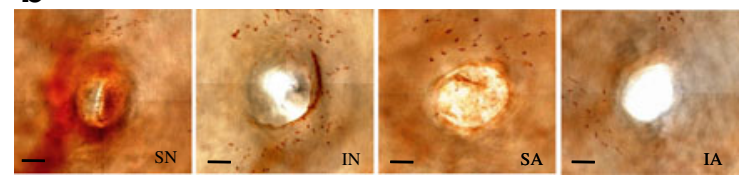

C

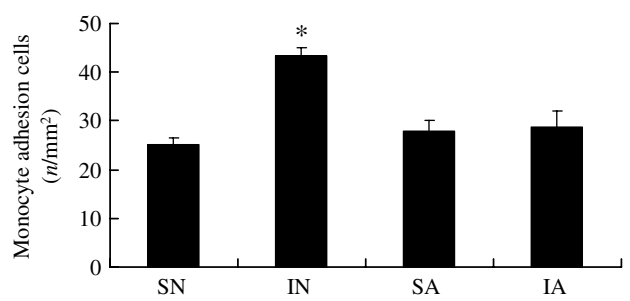

Fig. $3 \alpha-1$ and $\beta$-adrenoreceptor blocker inhibits the increase in monocyte adhesion to endothelial cells induced by hypoglycaemia in rat aorta. a Experimental protocol. b Representative en face photomicrographs of the aorta immunohistochemically stained with CD68 antibody in the saline without amosulalol (SN), insulin with amosulalol (IN), saline with amosulalol (SA) and insulin with amosulalol (IA) groups. Scale bar, $100 \mu \mathrm{m}$. c The density of adherent d

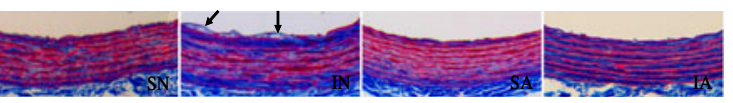

e

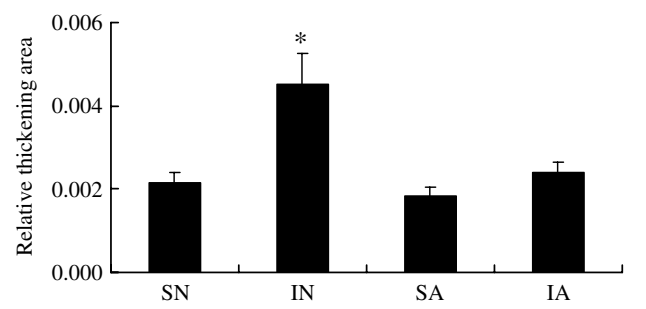

CD68-positive cells on endothelial cells at the age of 14 weeks $(n=6$ for each group). Data are mean $\pm \mathrm{SEM} ;{ }^{*} p<0.05$ vs the S, SA and IA groups. d Representative photomicrographs showing intimal thickening in the thoracic aorta stained with Azan in each group. Arrows, intimal thickness. Scale bar, $100 \mu \mathrm{m}$. e Area of the intima of the thoracic aorta in each group measured at the age of 14 weeks. Data are mean $\pm \mathrm{SEM} ;{ }^{*} p<0.05 \mathrm{v}$. the $\mathrm{S}, \mathrm{SA}$ and IA groups

\section{Discussion}

Hypoglycaemia is a frequently observed adverse effect in diabetic management, especially in patients using insulin and insulin secretagogues. Hypoglycaemia induces the release of adrenaline and noradrenaline from the adrenal medulla. Such an increase in catecholamine release may lead to ischaemia by increasing myocardial contractility, and is considered to play a role in ventricular tachycardia through prolongation of the QT interval [23]. However, the relationship between hypoglycaemia-induced catecholamine and vascular damage has not been fully elucidated. Here, we demonstrated in experimental animals that insulin induced hypoglycaemia and also provoked monocyte adhesion to endothelial cells in rat thoracic aorta. The results also confirmed that insulin-induced hypoglycaemia was associated with an acute increase in catecholamine and that this increase was suppressed by
Table 3 Metabolic variables and catecholamine levels in each group

Blood samples were collected from the various groups after an overnight fast

Data are mean \pm SEM

${ }^{\mathrm{a}} p<0.05$ vs saline without amosulalol group and both groups with amosulalol; ${ }^{\mathrm{b}} p<0.05$ vs saline without amosulalol group; ${ }^{\mathrm{c}} p<0.05$ vs insulin without amosulalol

\begin{tabular}{|c|c|c|c|c|}
\hline \multirow[t]{2}{*}{ Variable } & \multicolumn{2}{|c|}{ Without amosulalol } & \multicolumn{2}{|c|}{ With amosulalol } \\
\hline & Saline & Insulin & Saline & Insulin \\
\hline$n$ & 6 & 6 & 6 & 6 \\
\hline Fasting glucose $(\mathrm{mmol} / \mathrm{l})$ & $7.3 \pm 0.3$ & $6.8 \pm 0.3$ & $7.0 \pm 0.3$ & $6.6 \pm 0.3$ \\
\hline $\mathrm{HbA}_{1 \mathrm{c}}(\%)$ & $5.5 \pm 0.1$ & $5.0 \pm 0.1^{\mathrm{a}}$ & $5.5 \pm 0.1$ & $5.6 \pm 0.1$ \\
\hline Total cholesterol (mmol/l) & $2.08 \pm 0.06$ & $2.06 \pm 0.06$ & $1.80 \pm 0.06^{\mathrm{b}}$ & $1.87 \pm 0.09^{\mathrm{c}}$ \\
\hline HDL-cholesterol (mmol/l) & $1.60 \pm 0.04$ & $1.60 \pm 0.04$ & $1.41 \pm 0.04^{\mathrm{b}}$ & $1.46 \pm 0.07$ \\
\hline Triacylglycerol (mmol/l) & $0.46 \pm 0.07$ & $0.49 \pm 0.06$ & $0.45 \pm 0.08$ & $0.41 \pm 0.05$ \\
\hline Adrenaline $(\mathrm{nmol} / \mathrm{l})$ & $71.0 \pm 15.8$ & $160.1 \pm 35.5^{\mathrm{a}}$ & $74.1 \pm 17.2$ & $74.5 \pm 7.7$ \\
\hline Noradrenaline (nmol/1) & $32.0 \pm 6.3$ & $44.8 \pm 10.6$ & $28.3 \pm 5.4$ & $27.6 \pm 3.4$ \\
\hline Dopamine (nmol/1) & $0.5 \pm 0.1$ & $0.5 \pm 0.1$ & $0.5 \pm 0.1$ & $0.5 \pm 0.1$ \\
\hline
\end{tabular}


a
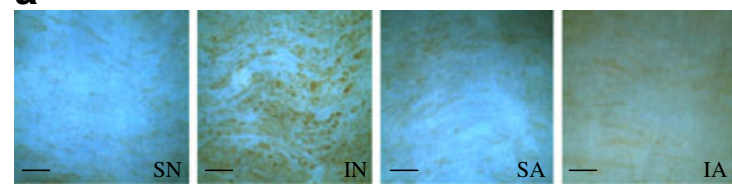

b

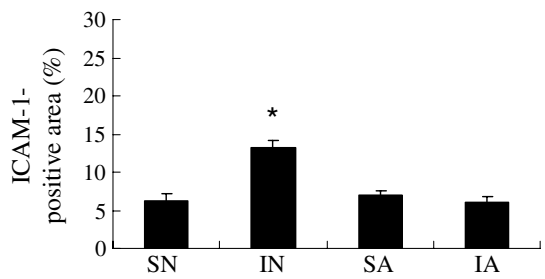

Fig. $4 \alpha-1$ and $\beta$-adrenoreceptor blocker inhibits the increased abundance of ICAM-1 and VCAM-1 that is induced by hypoglycaemia in endothelial surface of rat aorta. a Representative en face photomicrographs of the aorta immunohistochemically stained with ICAM-1 antibody in the saline without amosulalol (SN), insulin with amosulalol (IN), saline with amosulalol (SA) and insulin with amosulalol (IA) groups. Scale bar, $200 \mu \mathrm{m}$. b Percentage of ICAM-1positive area relative to total cross-sectional endothelial surface area at
C

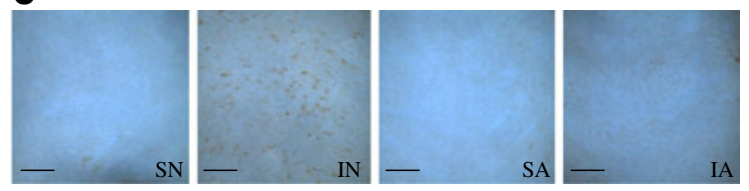

d

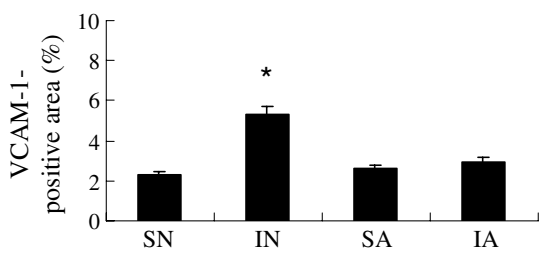

the age of 14 weeks ( $n=6$ for each group). Data are mean \pm SEM; ${ }^{*} p<0.05$ vs the SN, SA and IA groups. c Representative en face photomicrographs of the aorta immunohistochemically stained with VCAM-1 antibody in the groups as above (a, b). Scale bar, $200 \mu \mathrm{m}$. d Percentage of VCAM-1-positive area relative to total cross-sectional endothelial surface area at the age of 14 weeks ( $n=6$ for each group). Data are mean $\pm \mathrm{SEM} ; * p<0.05$ vs the $\mathrm{SN}, \mathrm{SA}$ and IA groups a

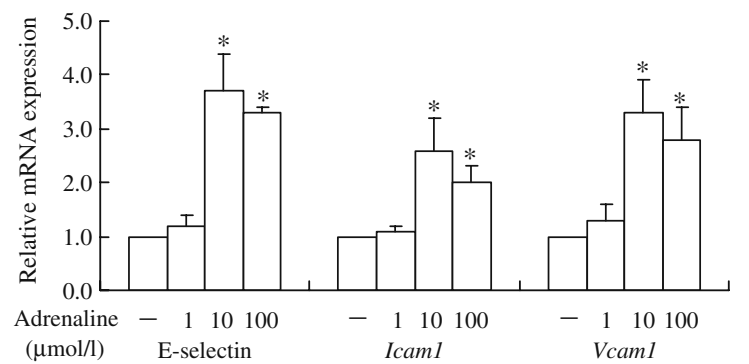

C

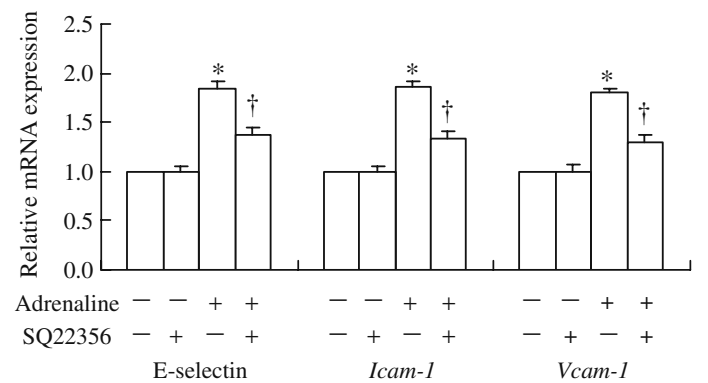

Fig. 5 Adrenaline increases the expression of genes encoding adhesion molecules in HUVEC. a HUVEC were incubated with the indicated concentrations of adrenaline for $24 \mathrm{~h}$. Then total RNA was isolated from HUVEC. The mRNA expression of the indicated genes was determined by quantitative RT-PCR. Relative gene expression represents the level of expression in HUVEC without addition of adrenaline set at 1.0 ( $n=4$ for each); ${ }^{*} p<0.05$ vs control. b HUVEC were co-incubated with the indicated concentrations of amosulalol and $10 \mu \mathrm{mol} / \mathrm{l}$ adrenaline for $24 \mathrm{~h}$. Then HUVEC were used for isolation of total RNA. The mRNA expression of the indicated genes was determined by quantitative RT-PCR. The relative gene expression is displayed as the level of expression in HUVEC without the addition of adrenaline at 1.0 ( $n=4$ for each); ${ }^{*} p<0.05$ vs control, ${ }^{\dagger} p<0.05$ vs b
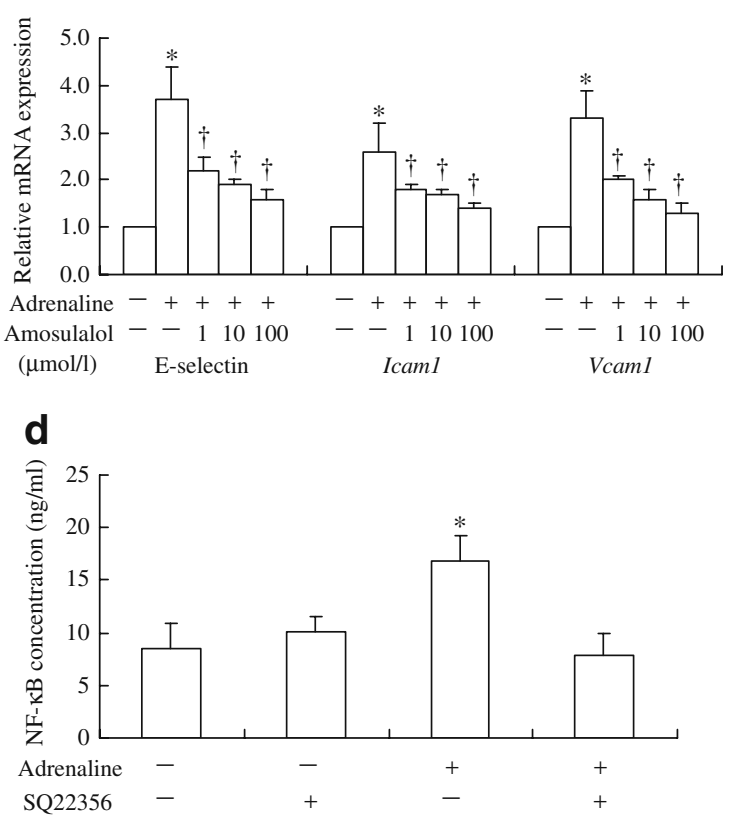

$10 \mu \mathrm{mol} / 1$ adrenaline. c After pre-incubation with or without $10 \mu \mathrm{mol} / 1 \mathrm{SQ} 22536$ for $30 \mathrm{~min}$, HUVEC were cultured with or without $10 \mu \mathrm{mol} / 1$ adrenaline for $24 \mathrm{~h}$. Then mRNA expression of each gene was determined by quantitative RT-PCR. The relative gene expression represents the level of expression in HUVEC without addition of adrenaline and SQ22536 set at $1.0 \quad(n=8$ for each); ${ }^{*} p<0.05$ vs without adrenaline and SQ2253, ${ }^{\dagger} p<0.05$ vs adrenaline without SQ22536. d After pre-incubation with or without $10 \mu \mathrm{mol} / 1 \mathrm{SQ} 22536$ for $30 \mathrm{~min}$, HUVEC were cultured with or without $10 \mu \mathrm{mol} / 1$ adrenaline for $45 \mathrm{~min}$. Then HUVEC were used to isolate nuclear proteins. The nuclear level of NF-kB p65 was determined by ELISA $(n=8) ; * p<0.05$ vs control or adrenaline with or without SQ22536 
simultaneous injection of glucose or administration of $\alpha-1$ and $\beta$-adrenoreceptor blocker. The enhanced monocyte adhesion to endothelial cells by insulin injection was also abrogated by simultaneous injection of glucose or the administration of $\alpha-1$ and $\beta$-adrenoreceptor blocker. Our results indicate that hypoglycaemia as such, and not insulin, provokes these changes. Also, our data suggest that the associated hypercatecholaminaemia induced by hypoglycaemia promotes the adhesion of monocytes to the endothelium of the thoracic aorta.

Recently, the counter-regulatory response to repetitive hypoglycaemia was investigated in intensive treatment of type 2 diabetes [24]. Repeated episodes of relatively mild hypoglycaemia reduced the counter-regulatory responses and impaired physiological defences against hypoglycaemia. The response of adrenaline, a key counter-regulatory hormone, to hypoglycaemia was reduced by $\sim 50 \%$ after repeated episodes of hypoglycaemia, but it never disappeared. However, it was also demonstrated that restoration of the counter-regulatory response could be achieved by short-term avoidance of hypoglycaemia [25]. In our model, the counter-regulatory response to repetitive hypoglycaemia was estimated to be kept in the experimental period. In addition to the temporal counter-regulatory response to repetitive hypoglycaemia, the basal adrenaline level was significantly higher after repetitive insulin-induced hypoglycaemia (Table 3). Indeed, basal adrenaline levels were significantly increased in insulin- and saline-injected groups compared with uninjected rats (data not shown). These data clearly suggest that repeated i.p. injection in itself causes chronic stress in rats, and thus may have increased basal adrenaline levels. It is also possible that the insulin injections result in repetitive hypoglycaemia-induced chronic stress plus stress caused by multiple injections, thus resulting in even greater increases of basal adrenaline level. Theoretically, this increased basal adrenaline level could modify monocyte adhesion to endothelial cells. The increased basal adrenaline level could be implicated in the enhanced monocyte adhesion to endothelial cells induced by repeated hypoglycaemia as well as by reactive increases of adrenaline levels.

Adrenaline receptor is a well-known $\mathrm{G}_{\mathrm{s}}$ proteincoupled receptor, thus the activation of adrenaline receptor results in increased cAMP concentration in endothelial cells [26]. Although several studies have investigated the role of cAMP in the modulation of adhesion molecule abundance, the findings obtained so far remain controversial. Activation of cAMP has been reported to inhibit the adhesion of polymorphonuclear leucocytes to nylon fibres $[27,28]$. In contrast, various agents, including adrenaline and noradrenaline, that are known to increase cAMP levels in endothelial cells promote adhesion of monocytes and leucocytes [29-31]. In agreement with the latter findings, we found that stimulation of cAMP by adrenaline was critical for increased expression of E-selectin, Icaml and Vcam1 in HUVEC in experiments using adenylate cyclase inhibitor.

$N F-k B$ is a nuclear transcription factor known to play an important role in regulating production of various adhesion molecules [20-22]. The present study showed that incubation of HUVEC with adrenaline resulted in translocation of NF- $\mathrm{kB}$ p 65 from the cytoplasm to the nucleus and that this translocation was abolished by cAMP inhibitor. This result is consistent with previous studies, in which increased intracellular levels of cAMP with adrenomedullin and corticotropin activated the production of adhesion molecules via NF$\mathrm{KB}$ transcription in HUVEC [32]. The present study is the first report of nuclear translocation of NF-kB p65 with subsequent overexpression of genes encoding adhesion molecules in response to increased cAMP levels elicited by adrenaline.

Other changes induced by hypoglycaemia can potentially play a role in the progression of atherosclerosis [33]. Several studies have reported that hypoglycaemia increases the levels of a variety of inflammatory cytokines $[9,10]$. These in turn cause endothelial dysfunction, resulting in increased risk of cardiovascular disease. Hypoglycaemia also induces abnormalities in platelet function and activation of the fibrinolytic system [11, 12]. Some of these events, including other counterregulatory hormones, are mediated by increased catecholamine levels. Thus, the sum of these responses can potentially adversely affect progression of atherosclerosis. Further studies are needed to elucidate the effects of other factors triggered by hypoglycaemia on monocyte adhesion to endothelial cells.

In conclusion, we have demonstrated in the present study that repetitive hypoglycaemia-induced adrenaline activity enhanced monocyte adhesion to endothelial cells in GK rat aorta, independently of the glucoselowering effect of insulin. In addition, the enhanced expression of adhesion molecules might, at least in part, be due to increased adrenaline levels induced by hypoglycaemia, which then trigger cAMP production, leading to NF-KB nuclear translocation in endothelial cells.

Acknowledgements We thank N. Daimaru, E. Magoshi and K. Nakamura for excellent technical assistance. This work was supported by grants from the Ministry of Education and Sports and Culture of Japan.

Duality of interest The authors declare that there is no duality of interest associated with this manuscript. 


\section{References}

1. Selvin E, Steffes MW, Zhu H et al (2010) Glycated hemoglobin, diabetes, and cardiovascular risk in nondiabetic adults. N Engl J Med 362:800-811

2. Gerstein HC, Miller ME, Byington RP et al (2008) Effects of intensive glucose lowering in type 2 diabetes. $\mathrm{N}$ Engl $\mathrm{J}$ Med 358:2545-2559

3. Patel A, MacMahon S, Chalmers J et al (2008) Intensive blood glucose control and vascular outcomes in patients with type 2 diabetes. N Engl J Med 358:2560-2572

4. Duckworth W, Abraira C, Moritz T et al (2009) Glucose control and vascular complications in veterans with type 2 diabetes. N Engl J Med 360:129-139

5. Graveling AJ, Frier MF (2010) Does hypoglycaemia cause cardiovascular events. Br J Diabetes Vasc Dis 10:5-13

6. Bonds DE, Miller ME, Bergenstal RM et al (2010) The association between symptomatic, severe hypoglycaemia and mortality in type 2 diabetes: retrospective epidemiological analysis of the ACCORD Study. BMJ 340:b4909

7. Frier BM, Corrall RJ, Davidson NM, Webber RG, Dewar A, French EB (1983) Peripheral blood cell changes in response to acute hypoglycaemia in man. Eur J Clin Investig 13:33-39

8. Collier A, Patrick AW, Hepburn DA et al (1990) Leucocyte mobilization and release of neutrophil elastase following acute insulin-induced hypoglycaemia in normal humans. Diabet Med 7:506-509

9. Galloway PJ, Thomson GA, Fisher BM, Semple CG (2000) Insulin-induced hypoglycemia induces a rise in C-reactive protein. Diabetes Care 23:861-862

10. Kitabchi AE, Umpierrez GE, Miles JM, Fisher JN (2009) Hyperglycemic crises in adult patients with diabetes. Diabetes Care 32:1335-1343

11. Dalsgaard-Nielsen J, Madsbad S, Hilsted J (1982) Changes in platelet function, blood coagulation and fibrinolysis during insulin-induced hypoglycaemia in juvenile diabetics and normal subjects. Thromb Haemost 47:254-258

12. Fisher BM, Hepburn DA, Smith JG, Frier BM (1992) Responses of peripheral blood cells to acute insulin-induced hypoglycaemia in humans: effect of alpha-adrenergic blockade. Horm Metab Res Suppl 26:109-110

13. Cybulsky MI, Iiyama $\mathrm{K}$, Li $\mathrm{H}$ et al (2001) A major role for VCAM-1, but not ICAM-1, in early atherosclerosis. J Clin Invest 107:1255-1262

14. Azuma K, Kawamori R, Toyofuku Y et al (2006) Repetitive fluctuations in blood glucose enhance monocyte adhesion to the endothelium of rat thoracic aorta. Arterioscler Thromb Vasc Biol 26:2275-2280

15. Otsuka A, Azuma K, Iesaki T et al (2005) Temporary hyperglycaemia provokes monocyte adhesion to endothelial cells in rat thoracic aorta. Diabetologia 48:2667-2674

16. Mita T, Otsuka A, Azuma K et al (2007) Swings in blood glucose levels accelerate atherogenesis in apolipoprotein E-deficient mice. Biochem Biophys Res Commun 358:679-685

17. Yamada H, Yoshida M, Nakano Y et al (2008) In vivo and in vitro inhibition of monocyte adhesion to endothelial cells and endothe- lial adhesion molecules by eicosapentaenoic acid. Arterioscler Thromb Vasc Biol 28:2173-2179

18. Arakawa M, Mita T, Azuma K et al (2010) Inhibition of monocyte adhesion to endothelial cells and attenuation of atherosclerotic lesion by a glucagon-like peptide-1 receptor agonist, exendin-4. Diabetes 59:1030-1037

19. Swaminath G, Xiang Y, Lee TW, Steenhuis J, Parnot C, Kobilka BK (2004) Sequential binding of agonists to the beta2 adrenoceptor. Kinetic evidence for intermediate conformational states. J Biol Chem 279:686-691

20. Whelan J, Ghersa P, Hooft van Huijsduijnen R et al (1991) An NF kappa B-like factor is essential but not sufficient for cytokine induction of endothelial leukocyte adhesion molecule 1 (ELAM-1) gene transcription. Nucleic Acids Res 19:2645-2653

21. Ledebur HC, Parks TP (1995) Transcriptional regulation of the intercellular adhesion molecule-1 gene by inflammatory cytokines in human endothelial cells. Essential roles of a variant NF-kappa B site and p65 homodimers. J Biol Chem 270:933-943

22. Iademarco MF, McQuillan JJ, Rosen GD, Dean DC (1992) Characterization of the promoter for vascular cell adhesion molecule-1 (VCAM-1). J Biol Chem 267:16323-16329

23. Robinson RT, Harris ND, Ireland RH, Lee S, Newman C, Heller SR (2003) Mechanisms of abnormal cardiac repolarization during insulin-induced hypoglycemia. Diabetes 52:1469-1474

24. Davis SN, Mann S, Briscoe VJ, Ertl AC, Tate DB (2009) Effects of intensive therapy and antecedent hypoglycemia on counterregulatory responses to hypoglycemia in type 2 diabetes. Diabetes 58:701-709

25. Lingenfelser T, Buettner U, Martin J et al (1995) Improvement of impaired counterregulatory hormone response and symptom perception by short-term avoidance of hypoglycemia in IDDM. Diabetes Care 18:321-325

26. Bacic F, McCarron RM, Uematsu S, Spatz M (1992) Adrenergic receptors coupled to adenylate cyclase in human cerebromicrovascular endothelium. Metab Brain Dis 7:125-137

27. Boxer LA, Allen JM, Baehner RL (1980) Diminished polymorphonuclear leukocyte adherence. Function dependent on release of cyclic AMP by endothelial cells after stimulation of beta-receptors by epinephrine. J Clin Invest 66:268-274

28. Boxer LA, Allen JM, Schmidt M, Yoder M, Baehner RL (1980) Inhibition of polymorphonuclear leukocyte adherence by prostacyclin. J Lab Clin Med 95:672-678

29. Sung CP, Arleth AJ, Storer B, Feuerstein GZ (1991) Modulation of U937 cell adhesion to vascular endothelial cells by cyclic AMP. Life Sci 49:375-382

30. Sung CP, Arleth AJ, Aiyar N, Bhatnagar PK, Lysko PG, Feuerstein G (1992) CGRP stimulates the adhesion of leukocytes to vascular endothelial cells. Peptides 13:429-434

31. Turunen JP, Mattila P, Renkonen R (1990) cAMP mediates IL-1induced lymphocyte penetration through endothelial monolayers. J Immunol 145:4192-4197

32. Hagi-Pavli E, Farthing PM, Kapas S (2004) Stimulation of adhesion molecule expression in human endothelial cells (HUVEC) by adrenomedullin and corticotrophin. Am J Physiol Cell Physiol 286:C239-C246

33. Desouza CV, Bolli GB, Fonseca V (2010) Hypoglycemia, diabetes, and cardiovascular events. Diabetes Care 33:1389-1394 